BISOGNIN, D.A.; AMARANTE, C.V.T.; DELLAI, J. Contribuição das folhas cotiledonares para o crescimento e estabelecimento de plântulas de cucurbitáceas. Horticultura Brasileira, Brasília, v.22, n.2, p.309-313, abril-junho 2004.

\title{
Contribuição das folhas cotiledonares para o crescimento e estabelecimento de plântulas de cucurbitáceas
}

\author{
Dilson Antônio Bisognin ${ }^{1}$; Cassandro V.T. do Amarante ${ }^{2}$; Jacso Dellai ${ }^{1}$ \\ ${ }^{1}$ UFSM, Depto. Fitotecnia, 97105-900 Santa Maria-RS; ${ }^{2}$ UDESC-CAV, C. Postal 281, 88502-970, Lages-SC; E-mail: \\ dilsonb@smail.ufsm.br
}

\section{RESUMO}

As cucurbitáceas apresentam germinação epigeal, cujos cotilédones têm a dupla função de fornecer substâncias de reserva e fotoassimilados para o crescimento e o estabelecimento da plântula. O objetivo deste trabalho foi quantificar o nível de dependência de plântulas de abóbora híbrida (Cucurbita maxima x C. moschata), melancia (Citrullus lanatus), pepino (Cucumis sativus) e porongo (Lagenaria siceraria) em relação às folhas cotiledonares para o crescimento e estabelecimento inicial. Foi efetuada a remoção de um ou dois cotilédones aos 3; 6; 9 e 12 dias após a emergência (DAE), comparando-se o crescimento das plântulas com o de plântulas controle (sem remoção). O crescimento inicial foi avaliado a cada três dias, da emergência até 21 DAE, determinando-se a taxa de expansão das folhas cotiledonares, o período de tempo até a equivalência entre área foliar e cotiledonar e a produção de matéria seca. A abóbora apresentou a maior taxa de expansão das folhas cotiledonares, o menor período até a emissão e expansão das folhas verdadeiras e a maior produção de matéria seca. As plântulas de abóbora e pepino apresentaram a maior dependência em relação às folhas cotiledonares. Os resultados obtidos mostram que danos às folhas cotiledonares, dependendo da espécie, da intensidade e da idade da plântula, podem afetar drasticamente o crescimento inicial e o estabelecimento das plântulas, com reflexos evidentes no rendimento de frutos em cucurbitáceas.

Palavras-chave: Cucurbita maxima x C. moschata, Citrullus lanatus, Cucumis sativus, Lagenaria siceraria, partição de fotoassimilados.

\begin{abstract}
Cotyledonary leaf contribution for growth and establishment of cucurbit seedlings

Cucurbit species have epigeal cotyledons adapted for both storage and photoassimilation functions. Seedling dependence on cotyledonary leaves for initial growth and establishment was quantified for hybrid squash (Cucurbita maxima x C. moschata), watermelon (Citrullus lanatus), cucumber (Cucumis sativus), and bottlegourd (Lagenaria siceraria). One or both cotyledons were excised at 3; 6; 9; and 12 days after emergence (DAE) and initial growth was compared to control seedlings (with intact cotyledons). Initial growth was quantified at 3-day intervals, from emergence until 21 DAE, by assessing expansion rate of cotyledonary leaves, time from emergence to achieve equivalence between leaf and cotyledonary area, and total dry matter production. Squash showed the highest expansion rate of cotyledonary leaves, the shortest time to achieve equivalence between leaf and cotyledonary area, and the highest total dry matter production. Squash and cucumber seedlings showed higher dependence on cotyledonary leaves than watermelon and bottlegourd. Impairment of cotyledonary leaves, depending on species, cotiledon damage level and seedling physiological age, can drastically affect initial growth and establishment of seedlings, therefore leading to yield reductions in cucurbits.
\end{abstract}

Keywords: Cucurbita maxima x C. moschata, Citrullus lanatus, Cucumis sativus, Lagenaria siceraria, photoassimilates partitioning.

\section{(Recebido para publicação em 25 de março de 2003 e aceito em 20 de março de 2004)}

A s cucurbitáceas representam impor tante família de plantas utilizadas para a produção de alimentos e fibras (Robinson e Decker-Walters, 1997). Entre 1996 e 1998, foram produzidas no mundo 14,5 milhões de toneladas, em média, de morangas, abóboras e melões, em uma área de 1,2 milhões de hectares (FAO, 1998). A melancia (Citrullus lanatus) é a única espécie de cucurbitácea cultivada no Brasil com dados isolados nas estatísticas da Organização das Nações Unidas para a Agricultura e Alimentação, com uma produção média, entre 1996 e 2002, de 643 mil toneladas produzidas em uma área de 80 mil hectares (FAO, 2002).

As diferentes espécies de cucurbitáceas apresentam desenvolvi- mento similar, tanto da parte aérea quanto do sistema radicular (Robinson e Decker-Walters, 1997). Estas espécies apresentam germinação epigeal, na qual o hipocótilo eleva os cotilédones acima do nível do solo. Os cotilédones de espécies com germinação epigeal têm a dupla função de fornecer substâncias de reserva e fotoassimilados para o crescimento e o estabelecimento da plântula, sendo que sementes maiores contêm maiores quantidades de reserva e também apresentam uma maior área cotiledonar inicial (Cooper e Fransen, 1974). Imediatamente após a emergência, os cotilédones iniciam uma fase de alta taxa de expansão, determinada pelo aumento do tamanho, e, no caso do pepino (Cucumis sativus), do número de células (Lovell e Moore, 1970). Como todas as estruturas de reserva estão localizadas acima da superfície do solo, as plântulas destas espécies não se estabelecem caso os tecidos cotiledonares sejam totalmente removidos (Nelson e Larson, 1984).

A expansão das folhas cotiledonares, produção de clorofila e presença de estômatos funcionais são adaptações que possibilitam a produção de fotoassimilados para sustentar o crescimento inicial e o estabelecimento das plântulas (Lovell e Moore, 1970). Desta forma, as plântulas de cucurbitáceas dependem das reservas da semente somente até a emergência, sendo o posterior crescimento e desenvolvimento dependente da atividade fotossintética das 
folhas cotiledonares (Penny et al., 1976). Isto traz vantagens adaptativas em relação a espécies com cotilédones somente com função de reserva, por não exigir uma rápida emissão de folhas verdadeiras para iniciar a produção de fotoassimilados. Por este fato, o crescimento inicial das cucurbitáceas é concentrado nos cotilédones, hipocótilos e raízes, em detrimento das folhas verdadeiras (Lovell e Moore, 1971). A função fotossintética das folhas cotiledonares, associada ao retardo do aparecimento de folhas verdadeiras, é determinante para o crescimento inicial e o estabelecimento das plântulas de cucurbitáceas. Entre as espécies, diferenças em área cotiledonar, capacidade de expansão das folhas cotiledonares, tempo até o surgimento e expansão das folhas verdadeiras e vigor inicial podem determinar o nível de dependência das plântulas em relação às folhas cotiledonares. $\mathrm{O}$ estabelecimento uniforme de um adequado estande de plantas é fundamental para aumentar o rendimento de frutos de alto valor comercial.

O objetivo deste trabalho foi quantificar o nível de dependência das plântulas em relação às folhas cotiledonares para o crescimento inicial e o estabelecimento de diferentes espécies de cucurbitáceas.

\section{MATERIAL E MÉTODOS}

Os experimentos foram conduzidos em casa de vegetação da Universidade Federal de Santa Maria (RS), em 2000/ 2001. As plântulas foram cultivadas em vasos (10 L) contendo $7 \mathrm{~kg}$ de solo, corrigido para $\mathrm{pH}$ 6,0 e adubado com 100; 200 e $150 \mathrm{mg} \mathrm{kg}^{-1}$, respectivamente, de $\mathrm{N}, \mathrm{P}_{2} \mathrm{O}_{5}$ e $\mathrm{K}_{2} \mathrm{O}$. O solo foi mantido suficientemente úmido, adicionando-se água sempre que necessário até próximo à capacidade de campo. A temperatura diurna foi de aproximadamente $30^{\circ} \mathrm{C}$ e a noturna de $20^{\circ} \mathrm{C}$, com uma variação de $\pm 5^{\circ} \mathrm{C}$ durante todo o período experimental. Os experimentos seguiram o delineamento completamente casualizado, com quatro repetições. Cada repetição correspondeu a um vaso com duas plântulas.

Foram utilizadas quatro espécies de cucurbitáceas, sendo duas de cultivares híbridas e duas de populações de polinização aberta. A cultivar 'Tetsukabuto' de abóbora é um híbrido inter-específico (Cucurbita maxima x $C$. moschata). A cultivar 'Calipso' de pepino também é um híbrido. A cultivar 'Charleston Gray' de melancia é originária de uma população de polinização aberta. A população 5 de porongo (Lagenaria sicerarial) também é originária de uma população de polinização aberta, não melhorada, e, em conseqüência, de alta variabilidade genética (Bisognin e Marchezan, 1988).

A dependência das plântulas em relação às folhas cotiledonares foi determinada através da remoção de um ou dois cotilédones aos 3; 6; 9 e 12 dias após a emergência (DAE), comparando o seu crescimento com o de plântulas controle (com ambas as folhas cotiledonares) aos 21 DAE. O crescimento inicial foi quantificado em intervalos de três dias, a partir da emergência até 21 DAE. As características avaliadas foram área cotiledonar e foliar e matéria seca das folhas cotiledonares, da parte aérea e do sistema radicular. A área cotiledonar e foliar foi determinada através de comparação da matéria seca de uma área conhecida de papel com a matéria seca de recortes dos perímetros dos cotilédones e folhas, traçados sobre o mesmo papel, como descrito por Amarante et al. (1995). A matéria seca das plantas foi determinada após a secagem das amostras em estufa de ar forçado a $65^{\circ} \mathrm{C}$ durante 72 horas. Com os dados de área cotiledonar e foliar foram obtidos dados de expansão das folhas cotiledonares (através da subtração da área cotiledonar por ocasião da emergência da área cotiledonar em cada época de avaliação) e de índice entre área total (somatório das áreas cotiledonar e foliar) e área cotiledonar.

Os dados foram submetidos à análise de variância pelo teste $\mathrm{F}$. O atendimento da exigência da homogeneidade das variâncias entre ambientes foi verificado através do teste do $\mathrm{F}$ máximo (Storck et al., 2000). As médias foram comparadas pelo teste de Tukey $(\mathrm{a}=$ 0,05 ) ou submetidas ao ajuste de modelos de regressão não lineares com o auxílio do programa SAS (SAS Institute, 1995).

\section{RESULTADOS E DISCUSSÃO}

$\mathrm{O}$ teste do $\mathrm{F}$ máximo mostrou que as variâncias entre ambientes são homogêneas, o que possibilita realização de análise conjunta dos dados. Foram ajustados modelos hiperbólicos do tipo $y=$ $\left(a^{*} x\right) /(b+x)$ para a relação entre dias após a emergência e expansão de área cotiledonar para todas as espécies de cucurbitáceas estudadas (Figura 1A), com valores de coeficientes de determinação $\left(R^{2}\right)$ iguais a 0,$938 ; 0,914 ; 0,979$ e 0,941 para abóbora, melancia, porongo e pepino, respectivamente. A abóbora foi a espécie que apresentou o maior incremento de área cotiledonar após a emergência, com valor máximo ajustado (coeficiente 'a' do modelo) de 45,67 cm² planta $^{-1}$. A melancia e o porongo apresentaram valores máximos de incremento de área cotiledonar de 29,55 e 29,82 $\mathrm{cm}^{2}$ planta ${ }^{-1}$, respectivamente. O pepino apresentou o menor valor, de 24,37 $\mathrm{cm}^{2}$ planta $^{-1}$. O coeficiente 'b' dos modelos ajustados [correspondente a constante de Michaelis-Menten (Km) em ensaios enzimáticos] representa o número de dias necessários, a partir da emergência, para as plantas atingirem metade do valor máximo de expansão das folhas cotiledonares, correspondendo a taxa de incremento inicial em área das mesmas. Os valores de coeficiente ' $b$ ' para abóbora, melancia, porongo e pepino foram de 1,$38 ; 3,06 ; 3,47$ e 4,31, respectivamente, indicando, nesta ordem, decréscimo nas taxas iniciais de expansão das folhas cotiledonares. Portanto, a abóbora apresentou a maior taxa de expansão das folhas cotiledonares e o menor período de tempo para atingir metade do valor máximo. A rápida expansão das folhas cotiledonares é vantajosa para a plântula, mesmo com pouca quantidade de reservas, para que logo após a emergência já apresente uma alta capacidade de produção de fotoassimilados (Lovell e Moore, 1970; Nelson e Larson, 1984).

A relação entre dias após a emergência e o índice entre área total e cotiledonar foi ajustada através de modelo exponencial $\left[y=\mathrm{a}+\mathrm{b}^{*} 2,7183^{(x-\mathrm{c}) / \mathrm{d}}\right]$ para abóbora e pepino, e através de modelo de Boltzman $[y=((a-b) /$ 
$\left.\left.\left(1+2,7183^{(x-c) / d}\right)\right)+b\right]$ para melancia e porongo (Figura 1B). Os modelos ajustados apresentaram valores de $\mathrm{R}^{2}$ iguais a 0,$989 ; 0,997 ; 0,990$ e 0,992 para abóbora, melancia, porongo e pepino, respectivamente. A abóbora foi a espécie que apresentou o mais rápido aparecimento de folhas verdadeiras, sendo que as plântulas atingiram a equivalência entre a área cotiledonar e foliar (índice =2) aos 5,6 DAE, seguida pela melancia, aos 8,3 DAE, pelo porongo, aos 8,9 DAE, e pelo pepino, aos 12,4 DAE. A abóbora, a melancia e o pepino apresentaram maiores taxas de aumento de área foliar (representado pelo rápido aumento do índice entre área total e cotiledonar) a partir do surgimento das primeiras folhas verdadeiras em relação ao porongo.

A taxa inicial de expansão das folhas cotiledonares, e a sua contribuição fotossintética, esteve associada com a velocidade de surgimento das folhas verdadeiras (representada pelo número de DAE para atingir a equivalência entre área foliar e cotiledonar) nas diferentes espécies de cucurbitáceas estudadas. A abóbora apresentou a mais alta taxa inicial de expansão das folhas cotiledonares, apresentando também menor período, a partir da emergência, para atingir equivalência entre área foliar e cotiledonar, além de apresentar rápida expansão de área foliar. As plântulas de pepino apresentaram as menores taxas de expansão das folhas cotiledonares, e, portanto, demoraram mais tempo para atingir a equivalência entre área foliar e cotiledonar. A melancia e o porongo apresentaram comportamento intermediário entre abóbora e pepino, mas as plântulas de melancia apresentaram maior aumento de área foliar a partir do momento em que ocorreu equivalência entre área foliar e cotiledonar. $\mathrm{O}$ pepino apresentou o maior período de tempo até atingir a equivalência entre área foliar e cotiledonar, mas, a partir deste momento, mostrou um rápido aumento de área foliar. Isto parece indicar que em pepino, o atraso na emissão de folhas verdadeiras é o resultado da baixa capacidade de expansão das folhas cotiledonares. Todavia, uma vez atingida uma área cotiledonar mínima, verifica-se um rápido aumento de área foliar. Em

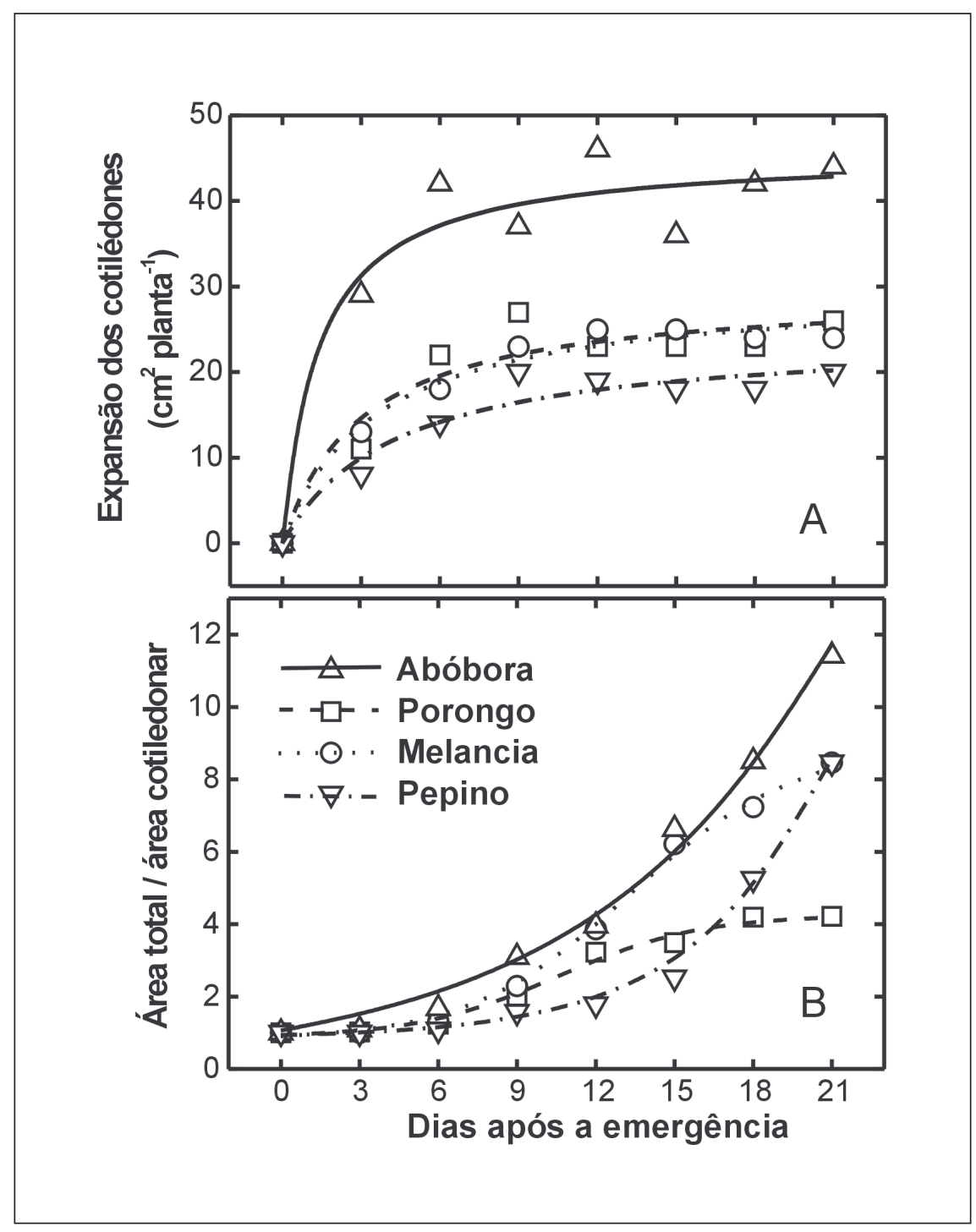

Figura 1. Expansão cotiledonar (A) e índice entre a área total (somatório das áreas cotiledonar e foliar) e a área cotiledonar (B) a partir da emergência de plântulas de cucurbitáceas. Santa Maria, UFSM, 2000/2001.

porongo, depois de atingida a equivalência entre área foliar e cotiledonar, ocorreu um lento aumento de área foliar, o que parece representar uma característica genética da própria espécie. Os drenos preferenciais de fotoassimilados a partir das folhas cotiledonares no porongo podem ser as raízes ao invés das folhas e ramos. Este menor aumento na área foliar não comprometeu o acúmulo de matéria seca total das plântulas de porongo, sendo, aos 21 DAE $\left(0,66\right.$ g planta $\left.^{-1}\right)$, pouco superior ao de pepino $\left(0,60 \mathrm{~g} \mathrm{planta}^{-1}\right)$. Os maiores valores de matéria seca aos 21 DAE foram observados em abóbora $\left(2,11 \mathrm{~g} \mathrm{planta}^{-1}\right)$ e melancia $(1,44 \mathrm{mg}$ planta $\left.^{-1}\right)$ (Tabela 1).
O efeito da remoção das folhas cotiledonares na produção total de matéria seca foi grandemente influenciado pela espécie e pela taxa de crescimento inicial, expressa em termos de taxa de expansão das folhas cotiledonares, de taxa de emissão e expansão das folhas verdadeiras e de produção total de matéria seca (Figura 1; Tabela 1). A taxa de crescimento inicial esteve diretamente relacionada com o tempo necessário até atingir o equilíbrio entre área total e cotiledonar para todas as espécies estudadas. No entanto, em melancia, porongo e pepino houve uma relação inversa entre a taxa de crescimento inicial e a duração do período de dependência das plântulas em relação às fo- 
Tabela 1. Produção total de matéria seca e percentagem de redução da matéria seca em relação ao tratamento controle (plântulas sem remoção dos cotilédones) de plântulas de cucurbitáceas submetidas à remoção de um ou dois cotilédones, em diferentes datas após a emergência. Avaliações feitas 21 dias após a emergência. Santa Maria, UFSM, 2000/2001.

\begin{tabular}{|c|c|c|c|c|c|c|c|c|}
\hline \multirow[b]{2}{*}{ Tratamentos $^{1}$} & \multicolumn{2}{|c|}{ Abóbora } & \multicolumn{2}{|c|}{ Melancia } & \multicolumn{2}{|c|}{ Porongo } & \multicolumn{2}{|c|}{ Pepino } \\
\hline & $\begin{array}{l}\text { Mat. seca } \\
\left(\text { g planta }^{-1}\right)\end{array}$ & $\begin{array}{c}\text { Redução } \\
\text { (\%) }\end{array}$ & $\begin{array}{l}\text { Mat. seca } \\
\left(\text { g planta }^{-1}\right)\end{array}$ & $\begin{array}{c}\text { Redução } \\
\text { (\%) }\end{array}$ & $\begin{array}{l}\text { Mat. seca } \\
\left.\text { (g planta }^{-1}\right)\end{array}$ & $\begin{array}{c}\text { Redução } \\
\text { (\%) }\end{array}$ & $\begin{array}{l}\text { Mat. seca } \\
\left(\text { g planta- }^{-1}\right)\end{array}$ & $\begin{array}{c}\text { Redução } \\
\text { (\%) }\end{array}$ \\
\hline Controle & $2,11 a^{2}$ & 0,0 & $1,44 \mathrm{a}$ & 0,0 & $0,66 \mathrm{a}$ & 0,0 & $0,60 \mathrm{a}$ & 0,0 \\
\hline 1cot./12dias & $1,97 a b$ & 6,5 & $1,30 \mathrm{a}$ & 10,0 & $0,61 \mathrm{ab}$ & 7,5 & $0,51 \mathrm{abc}$ & 13,9 \\
\hline 2cot./12dias & $1,67 \mathrm{bcd}$ & 21,2 & $1,18 \mathrm{a}$ & 17,9 & $0,64 a b$ & 1,5 & $0,45 a b c$ & 24,0 \\
\hline 1cot./9dias & $1,92 a b c$ & 9,5 & $1,37 \mathrm{a}$ & 5,1 & $0,64 \mathrm{ab}$ & 2,9 & $0,56 a b$ & 5,5 \\
\hline 2cot./9dias & $1,67 \mathrm{bcd}$ & 20,9 & $1,21 \mathrm{a}$ & 16,4 & $0,57 \mathrm{ab}$ & 12,7 & $0,43 b c$ & 27,6 \\
\hline 1 cot./6dias & $1,90 \mathrm{abc}$ & 10,0 & $1,29 a$ & 10,6 & $0,51 a b$ & 21,5 & $0,44 \quad b c$ & 27,0 \\
\hline 2cot./6dias & $1,52 \mathrm{~cd}$ & 28,1 & $1,20 \mathrm{a}$ & 16,8 & $0,30 \quad c$ & 54,5 & 0,18 & 69,0 \\
\hline 1cot./3dias & 1,43 & 32,1 & $1,24 a$ & 13,9 & $0,48 \quad b$ & 26,7 & 0,38 & 37,2 \\
\hline 2cot./3diasE & 0,72 & 65,6 & $0,37 \quad b$ & 74,7 & 0,18 & 71,8 & 0,00 & 100,0 \\
\hline Média & 1,66 & 21,6 & 1,18 & 18,4 & 0,51 & 22,1 & 0,39 & 33,8 \\
\hline C.V. $\%$ & 10,8 & & 10,2 & & 14,0 & & 15,6 & \\
\hline
\end{tabular}

${ }^{1} n$ cot. $=$ número de cotilédones removidos; $n$ dias= número de dias após a emergência para a eliminação de um ou dois cotilédones.

${ }^{2}$ Médias nas colunas seguidas pela mesma letra não diferem entre si pelo teste de Tukey a $5 \%$ de probabilidade de erro.

lhas cotiledonares. Nestas espécies, a remoção de ambos os cotilédones aos 6 DAE em melancia, aos 9 DAE em porongo e aos $12 \mathrm{DAE}$ em pepino não afetou significativamente o crescimento inicial das plântulas (Tabela 1). Além disto, a remoção de apenas um cotilédone pode ser efetuada cerca de três dias antes das datas descritas acima de remoção de ambos os cotilédones, sem que isto reduzisse o crescimento inicial das plântulas (aos 3 DAE, 6 DAE e 9 DAE para melancia, porongo e pepino, respectivamente). Entre estas espécies, o pepino foi mais afetado pela remoção dos cotilédones, pois a remoção de ambos os cotilédones aos $3 \mathrm{DAE}$ causou a morte das plântulas e a remoção de um cotilédone, na mesma época, reduziu a produção total de matéria seca aos 21 DAE em 37,2\%. A melancia foi a espécie menos afetada, pois a remoção de uma folha cotiledonar aos 3 DAE reduziu a produção total de matéria seca das plântulas em apenas $13,9 \%$ aos 21 DAE. O porongo apresentou um comportamento intermediário entre pepino e melancia, sendo que a remoção de uma folha cotiledonar aos 3 DAE reduziu em $26,7 \%$ a produção total de matéria seca das plântulas aos 21 DAE. A abóbora apresentou as mais elevadas taxas de crescimento inicial e uma única folha cotiledonar a partir de 6 DAE foi sufi- ciente para sustentar o crescimento inicial das plântulas. No entanto, a remoção de uma folha cotiledonar aos $3 \mathrm{DAE}$ reduziu em $32,1 \%$ a produção total de matéria seca das plântulas e a remoção de ambas folhas cotiledonares, mesmo aos 12 DAE, reduziu significativamente a produção total de matéria seca quantificada aos 21 DAE.

Os resultados obtidos confirmam observações de outros trabalhos, mostrando que o pepino é altamente dependente das folhas cotiledonares para o crescimento e estabelecimento das plântulas. Nesta espécie, as folhas cotiledonares apresentam maior capacidade fotossintética do que as folhas verdadeiras durante as fases iniciais de crescimento, sendo responsáveis por $80 \%$ e $25 \%$ das trocas totais de $\mathrm{CO}_{2}$, quando representam, respectivamente, $50 \%$ e $20 \%$ da área foliar total da plântula (Lasley e Garber, 1978). De maneira geral, as folhas verdadeiras das plantas somente atingem a fotossíntese líquida máxima quando ocorre a máxima expansão do limbo foliar (Hopkinson, 1964). Plântulas de abóbora também apresentaram elevada e prolongada dependência de área cotiledonar para o crescimento inicial. Todavia, enquanto pepino parece apresentar elevada dependência da folhas cotiledonares como resultado da reduzida taxa de expansão dos cotilédones, e, portanto, longo período para a emissão das folhas verdadeiras, a abóbora apresenta elevada dependência como conseqüência do rápido crescimento inicial e elevada demanda de fotoassimilados para a formação de folhas novas e sistema radicular. Mesmo apresentando elevado crescimento inicial, plântulas de abóbora conseguem manter a taxa de acúmulo de matéria seca com a remoção de um cotilédone aos 6 DAE (resultando em redução de apenas $10 \%$ na matéria seca total por plântula em relação ao controle), possivelmente como resultado da elevada expansão de área cotiledonar nesta espécie e do aumento da taxa fotossintética por unidade de área no cotilédone remanescente, resultante da redução da relação fonte e dreno como ocorre em folhas verdadeiras (Taiz e Zeiger, 1998). Todavia, a remoção de ambos os cotilédones, mesmo aos 12 DAE, comprometeu substancialmente o crescimento inicial (com redução de $21,2 \%$ na matéria seca total), demonstrando a elevada demanda de fotoassimilados produzidos nas folhas cotiledonares para atender a elevada demanda dos drenos mais próximos que são as raízes (Amarante et al., 1995), já que nesta fase as plantas apresentam uma boa área foliar (representada pela elevada relação entre área total e 
cotiledonar), capaz de atender a demanda dos drenos da parte aérea. Também, quando o suprimento de fotoassimilados é reduzido, neste caso pela remoção das folhas cotiledonares, a maioria dos fotoassimilados disponíveis é transportado para sustentar o crescimento de novos ramos e folhas em detrimento das raízes (Cooper e Fransen, 1974; Marschner, 1997; Penny et al., 1976), ou seja, o crescimento do sistema radicular nesta fase depende exclusivamente dos fotoassimilados produzidos nas folhas cotiledonares (Penny et al., 1976). Considerando que as cucurbitáceas são altamente sensíveis a deficiências hídricas no solo devido a baixa relação existente entre o sistema radicular e a parte aérea da planta, qualquer redução no crescimento do sistema radicular pode dificultar a absorção de água e de nutrientes minerais, principalmente os de baixa mobilidade (Marschner, 1997). A redução do crescimento e o atraso do estabelecimento das plântulas podem retardar o aparecimento de flores femininas e diminuir o período de duração do florescimento (Cantliffe e Omran, 1981) afetando a produção total e comercial de frutos das cucurbitáceas. Portanto, os produtores de cucurbitáceas devem estar atentos aos fatores bióticos e abióticos que podem causar qualquer dano às folhas cotiledonares, como é o caso da vaquinha (Diabrotica spp.), que normalmente causa danos severos às folhas cotiledonares, por ser preferencialmente atraída pelas altas concentrações de cucurbitacina existentes nestes tecidos (Chambliss e Jones, 1966).

Os resultados destes experimentos mostram claramente que danos às folhas cotiledonares, dependendo da espécie, da época e da intensidade, podem afetar drasticamente o crescimento inicial e até mesmo levar ao não estabelecimento das plântulas. Também, a taxa de crescimento inicial e o tempo necessário até atingir o equilíbrio entre área total e cotiledonar não são indicativos do nível de dependência das plântulas em relação às folhas cotiledonares para todas as espécies de cucurbitáceas.

\section{LITERATURA CITADA}

AMARANTE, C.V.T.; BISOGNIN, D.A.; CANCI, P.C. Contribuição das folhas cotiledonares para o crescimento inicial de plantas de abóbora híbrida cv. Tetsukabuto. Ciência Rural, Santa Maria, v.25, n.1, p.17-21, 1995.

BISOGNIN, D.A.; MARCHESAN, E. Avaliação de algumas populações de porongo - Lagenaria siceraria (Mol,) Standl, - cultivadas na região de Santa Maria, RS. Ciência Rural, Santa Matia, v.18, n.3-4, p.201-207, 1988.

CANTLIFFE, D.J.; JONES, C.M. Alteration of sex expression in cucumber by partial or total removal of the cotyledons. Journal of American Society of Horticultural Science, v.106, p.303-307, 1981.

CHAMBLISS, O.L.; JONES, C.M. Cucurbitacins: specific insect attractants in cucurbitaceae Science, v.153, p.1392-1393, 1966.

COOPER, C.S.; FRANSEN, S.C. Contribution of cotyledons to growth of the sainfoin seedling. Crop Science, v.14, p.732-735, 1974.

FAO. Production year book for 1998. Food and Agriculture Organization of the United Nations, Rome, v.52, p.128-144, 1998.
FAO. Faostat agriculture data for 2002, agriculture production, primary crops. Food and Agriculture Organization of the United Nations, Rome. Disponível em $<$ http://apps.fao.org/cgi-bin/ nph-db.pl? subset=agriculture $>$. Acesso em 27 jan. 2003.

HOPKINSON, J.M. Studies on the expansion of the leaf surface, IV, The carbon and phosphorus economy of a leaf. Journal of Experimental Botany, v.15, p.125-137, 1964.

LASLEY, S.E.; GARBER, M.P. Photosynthetic contribution of cotyledons to early development of cucumber. HortScience, v.13, p.191-193, 1978. LOVELL, P.H.; MOORE, K.G. A comparative study of cotyledons as assimilatory organs. Journal of Experimental Botany, v.21, p.10171030,1970 .

LOVELL, P.H.; MOORE, K.G. A comparative study of the role of the cotyledon in seedling development. Journal of Experimental Botany, v.22, p.153-162, 1971.

MARSCHNER, H. Mineral nutrition of higher plants. Second Edition. London: Academic Press, 1995. 492 p.

NELSON, C.J.; LARSON, K.L. Seedling growth. In: TESAR, M.B. (ed.). Physilogical basis of crop growth and development. American Society of Agronomy and Crop Science, Wisconsin. p. 93129. 1984.

PENNY, M.G.; MOORE, K.G.; LOVELL, P.H. The effect of inihibition of cotyledon photosynthesis on seedling development in Cucumis sativus L. Annual Botany, v.40, p.815824, 1976.

ROBINSON, R.W.; DECKER-WALTERS, D.S. Cucurbits. Crop Production Science in Horticulture n. 6. New York: CAB International, 1997, 226 p.

SAS Institute. The SAS system for Windows. Release 6.12. SAS Institute, Cary, NC. 1995.

STORCK, L.; GARCIA, D.C.; LOPES, S.J.; ESTEFANEL, V. Experimentação vegetal. Santa Maria: Universidade Federal de Santa Maria, 2000. 198 p.

TAIZ, L.; ZEIGER, E. Plant physiology. 2 ed. Sunderland: Sinauer Associates Publishers, 1998. $793 \mathrm{p}$. 